
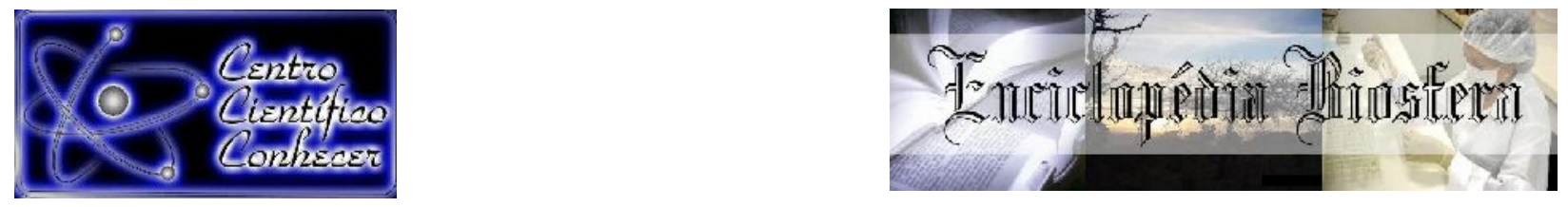

\title{
INFLUÊNCIA DO TRATAMENTO EM SEMENTES DE MILHO COM TIAMETOXAM NO TESTE DE CONDUTIVIDADE ELÉTRICA
}

\footnotetext{
Letícia dos Santos Hölbig Harter ${ }^{1}$; Fábio Schaun Harter $^{2}$; Cristiane Deuner; Francisco Amaral Villela; Géri Eduardo Meneghello.

${ }^{1}$ Professora do Curso de Agronomia SETREM, Três de Maio (RS) -Brasil, leticiaharter@setrem.com.br

${ }^{2}$ Engenheiro Agrônomo, Doutor em Ciência e Tecnologia de Sementes, Três de Maio (RS) - Brasil,

${ }^{3}$ Engenheira Agrônoma, Doutora em Ciência e Tecnologia de Sementes, Pelotas (RS) - Brasil,

${ }^{4}$ Eng ${ }^{\text {. }}$ Agrícola, Dr., Professor Associado do Programa de Pós-Graduação em Ciência e Tecnologia de Sementes, FAEM/UFPel. Caixa Postal 354, CEP 96010-900 Pelotas, RS.

${ }^{5}$ Eng. Agr. , Dr. do Programa de PPG Ciência e Tecnologia de Sementes, FAEM/UFPel,
}

Recebido em: 22/09/2018 - Aprovado em: 23/11/2018 - Publicado em: 03/12/2018 DOI: 10.18677/EnciBio_2018B56

\begin{abstract}
RESUMO
O milho é um dos produtos agrícolas mais importantes cultivados no mundo. No Brasil é de fundamental importância para o agronegócio e economia nacional. O inseticida Tiametoxam tem sido utilizado na forma de tratamento industrial pelas principais companhias produtoras de sementes de milho híbrido. Testes de vigor destinam-se, funcionalmente, a detecção de diferenças não perceptíveis no teste de germinação. O objetivo do trabalho foi avaliar se o tratamento em sementes de milho com o produto tiametoxam interfere na leitura do teste de condutividade elétrica. $O$ trabalho foi realizado no Laboratório Didático de Análise de Sementes, da Faculdade de Agronomia Eliseu Maciel, da Universidade Federal de Pelotas. Foram utilizadas sementes de milho híbrido SOMMA ${ }^{\circledR}$ de alta qualidade fisiológica. As sementes foram previamente tratadas. A qualidade das sementes foi avaliada através dos testes: Germinação, primeira contagem do teste de germinação, índice de velocidade de emergência em casa de vegetação, emergência de plântulas em casa de vegetação, comprimento da parte aérea e condutividade elétrica com leituras realizadas nos períodos de 16, 18, 20, 22 e 24 horas. O delineamento estatístico utilizado foi inteiramente casualizado com 4 repetições e as médias comparadas pelo teste de Tukey em nível de significância de $5 \%$. Para execução das análises estatísticas utilizou-se "Sistema de Análise Estatística para Microcomputadores Winstat. $O$ tratamento de sementes de milho com o produto tiametoxam não interfere na leitura do teste de condutividade elétrica. O período de 16 horas é adequado para o teste de condutividade elétrica em sementes de milho tratadas com tiametoxam.
\end{abstract}

PALAVRAS-CHAVE: tratamento de sementes, vigor, Zea mays. 


\title{
ELECTRICAL CONDUCTIVITY IN THE ASSESMENT OF PHYSIOLOGICAL QUALITY OF CORN SEEDS TREATED WITH THIAMETOXAM
}

\begin{abstract}
Corn is one of the most important agricultural products grown in the world. In Brazil, it isvery important for agribusiness and national economy. The insecticide Thiametoxam has been used in the form of industrial treatment by the main units producing hybrid corn seeds. Vigour tests are intended to detect non-perceptible differences in the germination test. The aim of the research was to evaluated if the product thiamethoxam interfering in the reading of the electrical conductivity test. The work was carried out in the Didactic Laboratory of Seed Analysis of the Agronomy School Eliseu Maciel of the Federal University of Pelotas. It was hybrid used corn seeds SOMMA® of high physiological quality. The seeds were previously treated. Seed quality was evaluated through the following tests: germination, first germination test count, greenhouse emergency index, emergence of seedlings in greenhouse, shoot length and electrical conductivity in the tests performed in the periods of 16 , 18, 20, 22 and 24 hours. The statistical design used was completely randomized with 4 replicates and as indicators compared by the Tukey test at a significance level of $5 \%$. To perform the statistical analyzes used, the "Statistical Analysis System for Winstat Microcomputers. The treatment of maize seeds with the thiamethoxam product does not interfere with the reading of the electrical conductivity test. The 16 hour period is suitable for the electrical conductivity test in corn seeds treated with thiamethoxam.
\end{abstract}

KEYWORDS: seed treatment, vigor, Zea mays.

\section{INTRODUÇÃO}

O milho (Zea mays) pode ser utilizado na alimentação humana, animal além de outros produtos. De acordo com os dados da CONAB (2018) o Brasil terá uma área de $16.636,8$ mil ha e produtividade média de $4.890 \mathrm{~kg} \mathrm{ha}^{-1}$, totalizando uma produção de aproximadamente 81 milhões de toneladas, sendo assim a cultura do milho no Brasil é de fundamental importância para o agronegócio e a economia nacional.

Devido à introdução do conceito que a semente é um agente de conteúdo tecnológico que carrega uma série de materiais como nutrientes, fungicidas, hormônios, incluindo entre outros os inseticidas; e ao mesmo tempo o valor da genética, tem aumentado significativamente as expectativas dos agricultores. $\mathrm{O}$ uso de inseticidas em tratamentos de sementes tem por objetivo, evitar possíveis perdas de produtividade, por ataques de insetos-praga a sementes e plântulas (CARVALHO et al., 2011).

O tiametoxam, inseticida sistêmico do grupo neonicotinóide, tem efeito bioativador, atuando na expressão dos genes responsáveis pela síntese e ativação de enzimas metabólicas, relacionadas ao crescimento da planta, alterando a produção de aminoácidos precursores de hormônios vegetais (CASTRO, 2006). O inseticida tiametoxam tem sido utilizado na forma de tratamento industrial pelas principais companhias produtoras de sementes de milho híbrido.

Testes de vigor destinam-se, funcionalmente, a detecção de diferenças não perceptíveis no teste de germinação. Sabe-se que o processo deteriorativo inicia pela degradação das membranas celulares, seguida por uma seqüência de eventos que culmina na perda do poder germinativo (DELOUCHE; BASKIN, 1973). Sendo 
assim, qualquer evento metabólico que antecede a perda da germinação pode servir como base para avaliar o vigor. Porém, quanto mais aquém da perda do poder germinativo estiver esse evento, mais sensível será o teste (KRZYZANOWSKI et al., 1999).

A utilização de métodos rápidos, confiáveis e de fácil execução para estimar a viabilidade das sementes é importante para o controle de qualidade nas empresas produtoras. Os testes rápidos mais estudados estão relacionados com eventos iniciais da seqüência de deterioração das sementes, dentre os testes 0 de condutividade elétrica é o mais promissor, com a vantagem adicional de fornecerem resultados em 24 horas (DIAS; MARCOS FILHO, 1996).

Diversos fatores estão diretamente relacionados com as sementes ou com os meios utilizados nos testes que podem interferir na leitura da condutividade elétrica, como a qualidade da água de embebição, o volume de água, a temperatura de embebição, tempo de embebição; o tamanho e o peso das sementes; a umidade inicial das sementes; o tratamento de proteção realizado nas sementes, pois o produto aderido as mesmas interfere na leitura da condutividade elétrica; entre outros (KRZYZANOWSKI et al., 1999).

Existe a necessidade de verificar o efeito de produtos químicos usados no tratamento de sementes nos resultados do teste de condutividade elétrica, que podem prejudicar as informações relacionadas com 0 vigor das sementes (KRZYZANOWSKI et al. 1999).

Para a International Rules For Seed Testing - ISTA, o teste de condutividade elétrica está padronizado para Pisum sativum, Phaseoulus vulgaris e Glycine Max, no entanto a mesma ressalta que deve-se ter cuidado nos resultados obtidos no teste de condutividade elétrica em sementes que sofreram tratamento com fungicida, pois alguns destes podem liberar solutos para o meio e alterar de forma significativa os resultados (ISTA, 2011).

Assim, o uso de testes de vigor torna-se útil no monitoramento da qualidade das sementes durante a produção, processamento e armazenamento, pois a perda de vigor precede a perda de germinação. O objetivo do trabalho foi avaliar se o tratamento de sementes de milho com o produto tiametoxam interfere na leitura do teste de condutividade elétrica.

\section{MATERIAL E MÉTODOS}

O trabalho foi realizado no Laboratório Didático de Análise de Sementes (LDAS), da Faculdade de Agronomia Eliseu Maciel (FAEM), da Universidade Federal de Pelotas (UFPel).

Foram utilizadas sementes de milho híbrido SOMMA ${ }^{\circledR}$ de alta qualidade fisiológica. As sementes foram previamente tratadas com Deltametrin e metil-pirifós e com fludioxonil + mefenoxan-m, fungicida recomendado para tratamento de sementes. As sementes foram tratadas com a molécula alvo deste trabalho, 0 tiametoxam, utilizando para isto um produto comercial com $350 \mathrm{~g}$ de ingrediente ativo por litro. As doses testadas foram: 0 e $0,7 \mathrm{mg}$ (dose recomendada pelo fabricante) de ingrediente ativo Tiametoxam por unidade de semente.

A qualidade das sementes foi avaliada através dos testes:

Germinação - conduzida com dezesseis subamostras de 50 sementes, constituindo quatro repetições de duzentas sementes para cada unidade experimental, em rolos de papel germitest umedecido com água destilada, na proporção 2,5 vezes o seu peso seco, em germinadores regulados a temperatura de $25^{\circ} \mathrm{C}$. As avaliações foram realizadas no quarto e sétimo dias após a semeadura, 
conforme as Regras para Análise de Sementes - RAS (BRASIL, 2009).

Primeira contagem do teste de germinação - avaliada conjuntamente com teste de germinação, computando-se a porcentagem de plântulas normais;

Frio - conduzida com 16 subamostras de 50 sementes, constituindo quatro repetições de duzentas sementes para cada unidade experimental, em rolos de papel germitest umedecido com água destilada na proporção 2,5vezes o seu peso seco, em refrigerador regulado a temperatura de $8^{\circ} \mathrm{C}$, durante sete dias. Após este período, foram transferidas para germinador a 25ㅇ e mantidas as condições do teste de germinação, conforme Krzyzanowski et al.(1999);

Emergência de plântulas em casa de vegetação - avaliada conjuntamente com a determinação do índice de velocidade de emergência em casa de vegetação climatizada, utilizando 5 subamostras de 25 sementes por unidade experimental. As avaliações foram realizadas no vigésimo primeiro dia após a semeadura, computando-se o número de plântulas emergidas com comprimento não inferior a 50 mm, conforme Krzyzanowski et al.(1999);

Comprimento da parte aérea - avaliada conjuntamente com a determinação emergência em casa de vegetação climatizada, utilizando 5 subamostras de 25 sementes por unidade experimental. As avaliações foram realizadas no vigésimo primeiro dia após a semeadura, mensurando-se 0 comprimento de cada plântula com régua graduada em $\mathrm{mm}$;

Condutividade elétrica - utilizaram-se quatro repetições de 25 sementes, provenientes da porção de sementes fisicamente puras. As sementes foram pesadas e colocadas em copos plásticos contendo $75 \mathrm{~mL}$ de água deionizada, mantidas a $25^{\circ} \mathrm{C}$. As leituras foram realizadas nos períodos de 16, 18, 20, 22 e 24 horas; determinada através da utilização do aparelho condutivímetro DIGIMED modelo DM-31, sendo o valor obtido, dividido pelo peso das sementes e os resultados expressos em mhos. $\mathrm{g}^{-1}$ de semente de acordo com Krzyzanowski et al. (1999).

O delineamento estatístico utilizado foi inteiramente casualizado com 4 repetições e as médias comparadas pelo teste de Tukey em nível de significância de $5 \%$. Para execução das análises estatísticas utilizou-se "Sistema de Análise Estatística para Microcomputadores Winstat (MACHADO, 2002).

\section{RESULTADOS E DICUSSÃO}

Observando os dados do teste de germinação (Tabela 1) é possível constatar a alta qualidade dos lotes estudados, pois todos apresentam germinação igual ou superior a 95\%. A semelhança observada entre os lotes no teste de germinação, provavelmente ocorreu em função deste ser conduzido em condições favoráveis de ambiente, o que, por sua vez, não garante o comportamento dos lotes quando encontram condições adversas no campo. Este fato constitui uma das limitações do teste indicando a necessidade de complementação dessas informações com os resultados de outros testes.

TABELA 1: Dados médios dos testes de germinação $(G)$, primeira contagem de germinação (1 $\left.{ }^{a} \mathrm{CG}\right)$ e frio $(F)$ de lotes de sementes de milho tratadas 
com (C) e sem (S) tiametoxam.

\begin{tabular}{|c|c|c|c|c|c|c|}
\hline \multirow{2}{*}{ Lotes } & \multicolumn{2}{|c|}{$\mathrm{G}(\%)$} & \multicolumn{2}{|c|}{$1^{\text {a }}$ CG (\%) } & \multicolumn{2}{|c|}{$F(\%)$} \\
\hline & C & $\mathrm{S}$ & C & S & C & $\mathrm{S}$ \\
\hline L1 & $96 \mathrm{bA}$ & $97 \mathrm{aB}$ & $85 \mathrm{aAB}$ & $84 \mathrm{aB}$ & $88 \mathrm{bC}$ & $98 \mathrm{aA}$ \\
\hline L2 & $96 \mathrm{bA}$ & $98 \mathrm{aAB}$ & 81 bB & $95 \mathrm{aA}$ & 89 bBC & $97 \mathrm{aA}$ \\
\hline L3 & $95 \mathrm{bA}$ & $98 \mathrm{aAB}$ & $76 \mathrm{bC}$ & $93 \mathrm{aA}$ & 91 bAB & $98 \mathrm{aA}$ \\
\hline L4 & $95 \mathrm{bA}$ & $99 a A$ & $87 \mathrm{bA}$ & $97 \mathrm{aA}$ & $92 \mathrm{bA}$ & $98 \mathrm{aA}$ \\
\hline
\end{tabular}

Médias seguidas da mesma letra minúscula na linha e maiúscula na coluna, não diferiram entre $\mathrm{s} i$ pelo teste de Tukey, ao nível de significância de 5\%.

Para todos os lotes estudados, constata-se que os lotes sem tratamento com tiametoxam apresentam germinação superior aos com tratamentos, em média de 2 pontos percentuais, pode-se inferir que deve ter ocorrido um efeito tóxico do produto sob a sementes, pois nas condições em que o teste é conduzido, não permite que o mesmo seja lixiviado. Tais resultados discordam dos observados por Almeida et al. (2015) em sementes de arroz; no qual constataram que o timetoxam causa incremento na germinação.

Nos lotes sem tratamento houve diferenças entre os lotes, onde o lote 4 foi superior ao lote 1. Nas sementes tratadas com tiametoxam observa-se que não houve diferenças entre os lotes.

$\mathrm{Na}$ variável primeira contagem de germinação (Tabela 1) apenas no lote 1 não houve diferença entre sementes tratadas e não tratadas. Para os demais lotes as sementes não tratadas obtiveram maiores porcentagens no teste de primeira contagem de germinação. Tais resultados divergem dos encontrados por Borges et al. (2015) em sementes de feijão; Gewehr et al. (2014) em sementes de trigo, Borges et al. (2016) em sementes de amendoim; nos quais os autores observaram maior porcentagem de sementes germinadas no teste de $1^{\underline{a}}$ contagem de germinação em sementes tratadas com Tiametoxam em comparação a testemunha.

Quando comparados os lotes tratados com tiametoxam observa-se que houve diferenças entre lotes sendo o lote 4 superior. Já nas sementes não tratadas apenas - lote 1 diferiu dos demais lotes. Embora a avaliação da primeira contagem seja realizada em conjunto com o teste de germinação, utilizando-se da mesma amostra, essa se mostrou mais sensível do que o teste de germinação, o que possibilitou a estratificação dos lotes. Lemes et al. (2015) encontraram diferenças entre lotes de sementes de abóbora tratadas com diferentes doses de Tiametoxam no teste de primeira contagem de germinação.

Os resultados do teste de frio (Tabela 1), novamente destacam que os lotes sem a aplicação do tiametoxam foram superiores aos com apenas tratamento com fungicidas. No entanto, em outros trabalhos constatou-se resposta positiva ao uso do tiametoxam no teste de frio em sementes de abóbora (LEMES et al., 2015), arroz (BORGES et al., 2014), feijão (BORGES et al., 2015). Nos lotes sem tratamento não houve diferenças entre eles, já nas sementes tratadas com tiametoxam há diferenças entre os lotes e o lote 4, que novamente mostrou superioridade. Resultados estes que corroboram com os encontrados no teste de primeira contagem, ratificando o lote 4 como aquele de qualidade superior aos demais lotes.

TABELA 2: Dados médios dos testes emergência (E) e comprimento de parte aérea (CPA) de lotes de sementes de milho tratadas com (C) e sem (S) tiametoxam. 


\begin{tabular}{ccccc}
\hline \multirow{2}{*}{ Lotes } & \multicolumn{2}{c}{$\mathrm{E}(\%)$} & \multicolumn{2}{c}{$\mathrm{CPA}(\mathrm{mm})$} \\
\cline { 2 - 5 } & $\mathrm{C}$ & $\mathrm{S}$ & $\mathrm{C}$ & $\mathrm{S}$ \\
\hline L1 & $86 \mathrm{bA}$ & $95 \mathrm{aA}$ & $310 \mathrm{bA}$ & $340 \mathrm{aA}$ \\
L2 & $91 \mathrm{aA}$ & $96 \mathrm{aA}$ & $310 \mathrm{aA}$ & $320 \mathrm{aA}$ \\
L3 & $93 \mathrm{aA}$ & $97 \mathrm{aA}$ & $300 \mathrm{aA}$ & $320 \mathrm{aA}$ \\
L4 & $92 \mathrm{aA}$ & $95 \mathrm{aA}$ & $300 \mathrm{aA}$ & $320 \mathrm{aA}$ \\
\hline
\end{tabular}

Médias seguidas da mesma letra minúscula na linha e maiúscula na coluna, não diferiram entre si pelo teste de Tukey, ao nível de significância de 5\%.

Nas variáveis emergência e comprimento de parte aérea (Tabela 2) apenas o lote 1 difere entre sementes com e sem tiametoxam no tratamento, corroborando os resultados encontrados por Gewehr et al. (2014), que em sementes de trigo de alto vigor, não observaram influência da dose de tiametoxan na emergência de plântulas. No entanto, Costa et al. (2017) observaram incremento na porcentagem de emergência de plântulas de Feijão caupi com o uso de tiametoxam.

Novamente observa-se que independentemente do tratamento não houve diferenças entre lotes. A similaridade entre os resultados, provavelmente ocorreu porque as condições utilizadas estimularam a emergência em campo. Tendo em vista que, a semeadura foi realizada sob condições favoráveis no início da época recomendada para cultura do milho, portanto, não encontrando dificuldades climáticas, as emergências observadas foram elevadas.

TABELA 3: Dados médios do teste de condutividade elétrica (umhos $/ \mathrm{cm} / \mathrm{g}$ ) em diferentes períodos de lotes de sementes de milho tratadas com (C) e sem (S) tiametoxam.

\begin{tabular}{|c|c|c|c|c|c|c|c|c|c|c|}
\hline & \multicolumn{10}{|c|}{ Períodos (horas) } \\
\hline \multirow{2}{*}{ Lotes } & \multicolumn{2}{|c|}{16} & \multicolumn{2}{|c|}{18} & \multicolumn{2}{c|}{20} & \multicolumn{2}{c|}{22} & \multicolumn{2}{c|}{24} \\
\cline { 2 - 11 } & C & S & C & S & C & S & C & S & C & S \\
\hline L1 & $65,80 \mathrm{aA}$ & $68,57 \mathrm{aA}$ & $72,42 \mathrm{aA}$ & $77,70 \mathrm{aA}$ & $77,62 \mathrm{aA}$ & $81,84 \mathrm{aA}$ & $84,68 \mathrm{aA}$ & $85,85 \mathrm{aA}$ & $87,24 \mathrm{aA}$ & $90,42 \mathrm{aA}$ \\
\hline L2 & $66,62 \mathrm{aA}$ & $69,13 \mathrm{aA}$ & $73,85 \mathrm{aA}$ & $71,18 \mathrm{aA}$ & $78,28 \mathrm{aA}$ & $80,79 \mathrm{aA}$ & $83,80 \mathrm{aA}$ & $84,72 \mathrm{aA}$ & $92,50 \mathrm{aA}$ & $89,45 \mathrm{aA}$ \\
\hline L3 & $66,85 \mathrm{aA}$ & $65,67 \mathrm{aA}$ & $76,40 \mathrm{aA}$ & $73,40 \mathrm{aA}$ & $80,07 \mathrm{aA}$ & $77,94 \mathrm{aA}$ & $87,39 \mathrm{aA}$ & $81,74 \mathrm{aA}$ & $91,48 \mathrm{aA}$ & $85,95 \mathrm{aA}$ \\
\hline L4 & $67,08 \mathrm{aA}$ & $71,88 \mathrm{aA}$ & $75,62 \mathrm{aA}$ & $80,55 \mathrm{aA}$ & $80,49 \mathrm{aA}$ & $84,57 \mathrm{aA}$ & $85,18 \mathrm{aA}$ & $90,37 \mathrm{aA}$ & $88,73 \mathrm{aA}$ & $93,91 \mathrm{aA}$ \\
\hline
\end{tabular}

Médias seguidas da mesma letra minúscula na linha e maiúscula na coluna, não diferiram entre si pelo teste de Tukey, ao nível de significância de 5\%.

Para a variável condutividade elétrica (Tabela 3 ) em todos os períodos avaliados não houve diferença entre os lotes com e sem tiametoxam, tampouco entre lotes. É possível observar em valores absolutos que há uma relação linear entre o aumento do período de embebição e aumento de lixiviados presentes na solução.

Os resultados concordam com os obtidos por Costa et al. (2018), nos quais os autores não observaram diferenças significativas no teste de condutividade elétrica entre sementes tratadas com inseticida e fungicidas e o tratamento controle. Os mesmos autores constatam que os valores de condutividade elétrica não terem diferenciado entre si estatisticamente é um indicativo de que os tratamentos aplicados não influenciaram no processo de degradação celular que tem como um de seus primeiros processos observados a desorganização do sistema de membranas celulares

Vazquez et al. (2014), concluíram que o tratamento de sementes de milho com os inseticidas (imidacloprid+thiodicarbe, thiamethoxam, fipronil, 
fipronil+piraclostrobyn+thiophanate-methyl, pirimiphos-methyl, deltamethrin e bifenthrin) e os fungicidas (fludioxonil+metalaxyl-M e captan) não interferem no resultado do teste de condutividade elétrica.

Para as variáveis germinação, primeira contagem de germinação e teste de frio (Tabela 1) observa-se a superioridade dos lotes sem tratamento em relação aos lotes com tratamento de tiametoxam, no entanto quando analisa-se as variáveis emergência e comprimento de plântula (Tabela 2), não há diferenças entre os lotes tratados e não tratados com tiametoxam, o que se faz inferir que quando utiliza-se substrato de papel não há lixiviação do produto utilizado no tratamento de sementes, causando efeito tóxico às mesmas. Nos testes em que utilizou-se outro substrato, que provavelmente possibilitou a lixiviação do produto, não apresentaram diferenças significativas entre os lotes de sementes de milho, independentemente de estar tratada ou não.

\section{CONCLUSÕES}

O tratamento de sementes de milho com o produto tiametoxam não interfere na leitura do teste de condutividade elétrica.

O período de 16 horas é adequado para o teste de condutividade elétrica em sementes de milho tratadas com tiametoxam.

\section{REFÊRENCIAS}

ALMEIDA, A.S.; LEMES, E.S.; JAUER, A.; MENEGHELLO, G.E.; TUNES, L.M. Efeito do tratamento de sementes com tiametoxam+lambda-cyhalothrin no desempenho fisiológico de cultivares de arroz. Revista Tecnologia \& Ciência Agropecuária, v.9, n.3. p. 49-54, 2015.

BORGES, A. T.; ALMEIDA, A. S.; DEUNER, C.; JAUER, A.; MENEGHELLO, G.E. Efeito do tiametoxam no tratamento de sementes de feijão. Revista Enciclopédia Biosfera, v.11 n.21, p.898-907, 2015.

BORGES, C.T.; ALMEIDA, A.S.; DEUNER, C.; TROYJACK, C.; JAUER, A.; MENEGHELLO, G.E. Efeito do tiametoxam sobre a qualidade fisiológica de sementes de amendoim. Revista Tecnologia \& Ciência Agropecuária, v.10, n.4, p 44-48, 2016.

BORGES, C.T.; ALMEIDA, A.S.; JAUER, A. TUNES, L.M.; MENEGHELLO, G.E. Efeito do tiametoxam na qualidade fisiológica de sementes de arroz submetido a armazenamento. Revista Enciclopédia Biosfera, v.10 n.19, p.882-889, 2014.

BRASIL. Ministério da Agricultura, Pecuária e Abastecimento. Regras para análise de sementes. Ministério da Agricultura, Pecuária e Abastecimento. Secretaria de Defesa Agropecuária. Brasília, DF: Mapa/ACS, 2009. 395p.

CARVALHO, N. L.; PERLIN, R.S.; COSTA, E.C. Thiametoxam em tratamento de sementes. Revista Monografias Ambientais, v.2, n.2, p. 158-175, 2011. Disponível em <http://dx.doi.org/10.5902/223613082314> DOI: http://dx.doi.org/10.5902/223613082314

CASTRO, P.R.C. Agroquímicos de controle hormonal na agricultura tropical. Piracicaba: ESALQ, (Série Produtor Rural, 32). 2006. 46p. 
CONAB. Companhia Nacional de Abastecimento. Acompanhamento de safra brasileira de grãos. Décimo segundo levantamento, v.5, safra 2017/2018, n.12. Brasília: Conab, 2018, 155p

COSTA, E. M.; NUNES, B.M.; VENTURA, M. V.A.; ARANTES, B. H.T.; MENDES, G.R. Efeito fisiológico de inseticidas e fungicida sobre a germinação e vigor de sementes de soja (Glycine max L.). Científic@ - Multidisciplinary Journal, v.5, n.2, p 77-84,2018. Disponível em < DOI: 10.29247/2358-260X.2018v5i2.p77-84> DOI: 10.29247/2358-260X.2018v5i2.p77-84

COSTA, R. Q.; SANTOS, J.L.; PORTO, J. S.; VASCONCELOS, R.C.; CANGUSSU, A. C. V.; MORAIS, O. M. Ação do insecticida tiametoxame aplicado às sementes na emergência e vigor de plântulas de Vigna unguiculata (L.) Walp. Revista Ciências Agrárias, v.40, n. $3, \quad$ p. 608-615, 2017. Disponível em < http://dx.doi.org/10.19084/RCA16151>.

DELOUCHE, J. C.; BASKIN, C. C. Accelerated aging techniques for predicting the relative storability seed lots. Seed Science and Technology, Zurich, v.1, n.2, p.427452, 1973.

DIAS, D.C.F.S.; MARCOS-FILHO, J. Testes de condutividade elétrica para avaliação do vigor de sementes de soja (Glycine $\max$ (L.) Merrill). Scientia Agricola, v.53, n.1, p.31- 42, 1996. Disponível < http://dx.doi.org/10.1590/S0103-90161996000100005>

GEWEHR, E.; RADKE, A.K.; CORRÊA, O.O.; REIS, B. B.; BARROS, A.C.S.A. Qualidade fisiológica inicial de sementes de trigo tratadas com thiamethoxam. Revista Enciclopédia Biosfera, v.10 n.19, p.1596-1605, 2014.

INTERNATIONAL SEED TESTING ASSOCIATION. International rules for seed testing. Edition, 2011. Bassedsdorf, Switzerland, 2011.

KRZYZANOWSKI, C.F., VIEIRA, R.D., FRANÇA NETO, J.B. Associação Brasileira de Tecnologia de Sementes, Comitê de Vigor de Sementes. Londrina: ABRATES, 1999. 218p.

LEMES, E.S., ALAMEIDA, A.S.; MENEGHELLO, G.E.; TUNES, L.M.; VILLELA, F.A. Germinação e vigor de sementes de abóbora tratadas com tiametoxam. Revista Pesquisa Agropecuária Tropical, v. 45, n. 1, p. 122-127, 2015.

MACHADO, A. Programa de Análise Estatística - winstat 2, 2002. Disponível em: http://www.ufpel.tche.br/ amachado/winstat/ software. Acesso em: 15 jun. 2011.

VAZQUEZ, G.H.; CARDOSO, R.D.; PERES, A.R. Tratamento químico de sementes de milho e o teste de condutividade elétrica. Bioscience jornal, v.30, n.3, p. 773$781,2014$. 